\title{
LA LITERATURA DIGITAL EN ESPAÑOL: ESTADO DE LA CUESTIÓN
}

\author{
Dolores Romero López \\ Universidad Complutense de Madrid \\ dromero@filol.ucm.es
}

\begin{abstract}
Resumen: ¿De qué forma la literatura en general y la española en particular hará frente a los retos de Internet? Si nos planteamos que el espacio virtual no es sólo comunicación e información sino, además, es cultura quizá podremos acercarnos sin menos prejuicios a la impronta que la era digital está dejando en la creación literaria. Estamos en los albores de lo que se ha dado en llamar literatura digital, es decir, literatura que no se puede imprimir, que se escribe y compone para ser leída en Internet principalmente. En este estado de la cuestión vamos a presentar a los lectores cómo surge la literatura digital en español y cuales son sus primeras claves interpretativas. Algunas de las características atribuibles a la literatura digital —la experimentación de la colectividad y la ruptura de la linealidad narrativa- son demostrables en los relatos literarios de la novela colectiva y experimental hispánica. Además contamos con algunos ejemplos pioneros de obras literarias digitales escritas en español en los que se puede comprobar ciertos valores específicos que brotan de su propia virtualidad. Hemos presentado nuestro particular acercamiento a dichas obras teniendo en cuenta distintas vías de lectura.
\end{abstract}

Palabras clave: Literatura Digital, Lectura Digital, Poesía Digital, Narrativa Digital, Literatura Digital En Español

Summary: How is Lliterature in general and the Spanish one in particular reacting to the challenges of the Internet era? If we consider that the virtual space is not only communication and information but also culture, perhaps we could approach the imprint that the digital age is leaving in literary creation. We are at the beggining of what has been called digital literature, i.e., literature that cannot be printed, which is written and composed to be read on the Internet. In this article we are going to introduce to readers how the Spanish digital literature emerged and which are their first interpretative parameters. Some characteristics of digital literature - experimentation of the collectivity and the breakdown of the narrative linearity - are demonstrable in the literary stories of Hispanic collective and experimental novel. We also have some pioneers examples of digital literary works written in Spanish where you can check certain specific values that sprout from her own potentiality. We discuss our own approach to this digital works taking into account different ways to read them.

Key words: Digital Literature, Digital Reading, Spanish Digital Poetry, Spanish Digital Narrative, Spanish Ditigal Literature,

En la actualidad ya no sólo utilizamos el formato digital para enviar mensajes electrónicos u obtener información de Internet, sino que el espacio numérico se va convirtiendo poco a poco en un entorno cultural en el que repensar las formas artísticas. Ya no hablamos de

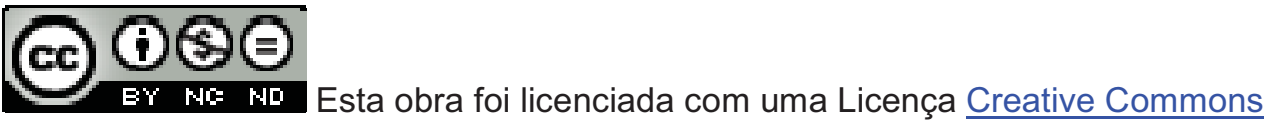

Texto Digital, Florianópolis, v. 7, n. 1, jan./jun. 2011. ISSNe: 1807-9288 
las TIC sino de las TIC+Cultura (Romero López, 2009). Las redes digitales generan comunidades virtuales en las que lo visual/textual, oral/escrito, comunicativo/cultural convergen en lo local y universal para dar una dimensión global al ser humano. La cibercultura no es únicamente un ciberespacio donde lo genuino queda sometido al poder de la relativización virtual, donde la identidad se difumina en la conciencia social y lo local se globaliza. Progresivamente las posturas más radicales, la de los apocalípticos, por un lado, y la de los fanáticos de la informática por otro, se van atenuando para dejar paso a una reflexión en la que participan teóricos de la literatura y de la comunicación, creadores y público en general. La cultura digital va recorriendo unas dinámicas de producción y consumo que han evolucionado desde los planteamientos utópicos de Andy Hawk (1993) y Pierre Lévy (2007), a los antropológicos de Arturo Escobar (1994) o David Hakken (1999) y los epistemológicos de Lev Manovich (2003) y Lister (2003). Quizá la clave más peculiar de la identidad cibercultural está en que dicho concepto abarca lo global sin renunciar a lo particular, es una universalidad sin totalidad, como apunta Pierre Lévy (2007: 223). Por lo tanto, al mismo tiempo que necesitamos universalizar el conocimiento científico y los dogmas religiosos, necesitamos sentir la diversidad, pero apropiándonos de lo nuestro. Lo mismo ocurre, como vamos a comprobar en este artículo, con la creación literaria, una de las formas de cultura que más se ha visto afectada por este proceso de glocalización cultural (Bolivar, 2001, Robertson, 2003).

La crítica especializada ha ido sumando una serie de clichés que se van repitiendo en el análisis de los textos literarios digitales. Así, teniendo como referencia la definición de hipertexto (Landow, 1995, 2009) basada en el análisis de un escueto número de obras experimentales - como por ejemplo Afternoon, a story de Michael Joyce y Victory Garden de Stuart Moulthrop - , los teóricos centran sus reflexiones en cinco aspectos: la colectividad (Moulthop y Kaplan, 1991, Casacuberta 2003), la muerte del autor (Toschi, 1996), la ruptura de la linealidad (Bernstein, 1988, 1990, 1991, 1994, Aarseth, 1993 1997), la desmitificación del canon y la democratización del arte (Gómez Trueba, 2005). El texto literario digital ha de ser multilineal, multimedia, múltiple en contenido y en forma, interactivo y dinámico (Pajares, 2004). Dichos adjetivos recogen distintas aportaciones teóricas postmodernas basadas en la intertextualidad de Julia Kristeva, las lexías de Roland Barthes, la polifonía textual de Mikhail Bakhtin, las redes de poder de Michael 
Foucault, los rizomas de Gilles Deleuze y Félix Guattari, el texto expansivo derridiano y la evolución de los sistemas de comunicación de Wolfgang Iser y Stanley Fish.

Por tanto, si es posible el planteamiento universal/estandarizado de la literatura digital, también es factible recabar información sobre lo específico de esta literatura, aunque aquí como criterio de especificidad vamos a seleccionar lo lingüístico (la lengua española) y no lo geográfico (hablada en todo el mundo). Y como aproximación a la literatura digital escrita en español cabe hacer dos recorridos, que son los que aquí ofrezco en diferentes apartados. Por un lado, hay que ver cuáles de esas características atribuidas a la literatura digital las encontramos ya en los textos literarios, tanto españoles como hispanoamericanos, publicados en papel. Por otro lado, hay que reflexionar sobre qué textos digitales son específicamente literarios y en base a qué criterios para terminar haciendo una apuesta de lectura e interpretación de dichos textos.

\section{1 - EL SURGIMIENTO DEL RELATO CON CARACTERÍSTICAS HIPERTEXTUALES}

Existieron hipertextos impresos antes de existir el hipertexto digital. En general, las obras que se citan como antecedentes de la escritura hipertextual son seleccionadas teniendo en cuenta dos criterios: su deseo de experimentar la colectividad y la ruptura de la linealidad narrativa (Douglas, 1992).

\section{1 - La experiencia de la colectividad}

El valor de la creatividad como valor social que genera conocimiento basado en la comunicación colectiva es una de las características básicas de Internet. David Casacuberta (2003) desarrolla en su libro Creación colectiva. En Internet el creador es el público la idea de que uno de los cambios más radicales que las nuevas tecnologías de la información y la comunicación están produciendo en nuestra cultura es precisamente la posibilidad de creación colectiva. Es este un concepto poderoso que nos permite asumir otros conceptos parciales como el de la interactividad, el final abierto, el hipertexto o la democratización del arte (Moulthrop, Kaplan, 1991). 
Hoy en día, la creación literaria impresa suele ser obra de sólo un autor. Sin embargo, si nos adentramos en la historiografía literaria española nos damos cuenta de que la creación literaria surge bajo los parámetros de la creación colectiva. Las jarchas, la lírica tradicional hispánica y los romanceros —como manifestación hispánica de las baladas europeas-demuestran, en sus variantes, su carácter abierto y sus interferencias, su pertenencia a una colectividad que la ha venido recreando oralmente hasta nuestros días. Más allá del desarrollo de la imprenta y del liberalismo económico de los siglos XVIII y $\mathrm{XIX}$, que exaltaron la razón individual, la originalidad del genio creativo, la propiedad intelectual y los derechos de autor (Moreno Hernández, 1998) y que terminaron desprestigiando la idea de colectividad creativa, podemos encontrar algunos ejemplos aislados de creación literaria colectiva, que ya no se interpreta como un proceso innato a la creación sino más bien como un experimento extravagante, una forma anómala de construcción del texto que se considera un antecedente de los experimentos colectivos producidos en el entorno electrónico del siglo XXI. Un ejemplo de novela colectiva, ideada por Sinesio Delgado, es Las vírgenes locas, que fue publicada por entregas en las páginas de la revista del Madrid cómico, en 1886. Sinesio Delgado pretendía construir, según sus propias palabras, "una novela sin género, ni plan determinado y de la cual cada capítulo ha de ser original de un autor diferente, que lo firmará y se retirará de la palestra" (Sanz Villanueva, 2001: 25). Otro ejemplo de creación colectiva, en este caso en el ámbito del Surrealismo, es el popular Cadáver exquisito. Se trataba de que cada integrante del grupo realizara parte de una obra sin conocer (completamente) las partes restantes, de tal manera que se construyera una especie de collage colectivo de palabras o imágenes. En el clima colectivista que reina en los jóvenes de filiación revolucionaria de la República surgen dos novela colectivas de Ramón J. Sender: Historia de un día de la vida española (1935), publicada en el número 5-6 de Tensor, cuya autoría se atribuye a Alberti, Altolaguirre, Arconada, Carranque de Ríos o Cernuda. Asimismo, en la revista política de agitación Línea, también dirigida por Ramón J. Sender, entre 1935 y 1936, se publicó la novela colectiva, Suma y sigue o el cuento de nunca acabar, "novela picaresca de nuestros días" (Santonja, 2001: 62). Junto a esos intentos novelísticos existen paralelamente otros que se hacen eco del aspecto lúdico de lo colectivo entre los que habría que citar Cien por cien, (1936) en cuya elaboración participaron Concha Espina, Pedro Mata, Tomás Borrás, Artemio Precioso o el mismo Benjamín Jarnés. En los años 
cuarenta hemos de recordar el proyecto Nueve millones, novela colectiva, surgida de un programa radiofónico, publicada por Afrodisio Aguado, en 1944, en la que participaron 18 autores, Camilo José Cela entre ellos.

En las Webs escritas en español, aun siendo menos frecuente este tipo de experimentos, también podemos encontrar numerosos ejemplos. El escritor Lorenzo Silva, en el año 2001 decidió embarcarse, junto a Círculo de Lectores, en el desafío de construir una novela con la ayuda y la participación de los lectores. La fórmula era sencilla: durante diez semanas y a través de Internet, en la página http://www.circulo.es/, el público votaría por una serie de alternativas que, paso a paso, irían construyendo la historia. Así fue surgiendo, con el veredicto de la mayoría, La isla del fin de la suerte, una intensísima novela negra, de profundas aristas psicológicas, escenificada en un desolador islote del Báltico. En aquel lugar será congregado un selecto grupo de invitados, quienes se verán sometidos a las veleidades de una mente perversamente traviesa, dispuesta a hacerles pasar una extravagante prueba de muertes y asesinatos. Una experiencia límite, capaz de resquebrajar las fronteras de la realidad y de hacer comprender la vida como un juego, una broma, o incluso, como una gigantesca charada de un mago caprichoso. La novela sería publicada en papel en 2001 por el Círculo de Lectores y en 2002 por Booklet, en edición de bolsillo.

Otro ejemplo de estos proyectos de creación colectiva pudiera ser la novela La rebelión de los delfines, iniciativa llevada a cabo en el año 2000 por la página Web del periódico El Mundo. Se trataba de hacer una novela colectiva y por entregas, creada tanto por escritores profesionales (Francisco Umbral, Espido Freire, Carmen Rigalt, José María Merino, Eduardo Mendicutti y Javier Tomeo) como por aficionados. Más tarde, la Web de El Mundo llevó a cabo otro proyecto similar a este, la novela La muerte atravesó el paraninfo (http://www.elmundo.es/especiales/2003/11/cultura/novela/), aunque en este caso restringiendo mucho el número de colaboradores, ya que está escrita "a cuatro manos" por Raúl del Pozo y Espido Freire. Por su parte, la revista electrónica Caminos de Pakistán (http://www.caminosdepakistan.com/) también propone a sus usuarios la creación de una novela y un guión colectivos. Muchas son las novelas que actualmente se difunden en la red a través de unos mecanismos similares: Autopista de peaje. Una 
historia Ilena de salidas (http://www.geocities.com/remoalbatros/), La señora (http://www.imaginando.com), Caminos de Pakistán (http://www.caminosdepakistan.com), $\quad 0 \quad$ Textos caducos (http://es.geocities.com/textoscaducos/index.htm). El hecho de que estos proyectos de creación en colectividad se lleven a cabo a través de Internet es justificado por quienes lanzan la iniciativa en función de la velocidad y facilidad que este nuevo medio otorga a la comunicación. Lo que habría que preguntarse es si este tipo de creaciones sufren alguna alteración o cambio trascendente por el mero hecho de ser concebidas y realizadas en línea.

Esta idea de colectividad literaria también la encontramos en los relatos hipertextuales del proyecto experimental titulado Un mar de historias creado por tres alumnos de posgrado de la Facultad de Sociología de la Universidade da Coruña Xiomara Acosta, María Jesús Vidal y Álvaro López Santos, en el que se combinan elementos de la literatura oral tradicional con aspectos tradicionales auditivos. Sus autores pretender dar a conocer diferentes leyendas gallegas del mar a través de la literatura interactiva, en la cual se pueden escoger en todo momento los trayectos de lectura, eligiendo qué nexos establecer y qué personajes (Toñito, Gervasio o Capitán Risco) asumirán el rol narrativo. Llama la atención que este hipertexto asuma el carácter oral de la literatura tradicional como base de sus narraciones. En la tradición oral el público tiene la facultad de intervenir en el desarrollo de la secuencia de acontecimientos relatados, secuencia que el narrador puede alterar, contraer o expandir, en virtud de la respuesta de sus oyentes. Esa es una dinámica que resulta próxima a la que se produce entre usuario, narrador y texto en los entornos interactivos. La tradición oral supone la presencia del narrador entre el auditorio, en las historias virtuales existe un alto grado de participación interactiva por parte de los usuarios.

\section{2 - Ruptura de la linealidad narrativa}

Otra de las características del hipertexto literario es su funcionamiento a partir de enlaces que permiten la navegación del lector y un grado de apertura discursiva mayor que el de la obra impresa (Cotte, 1999). Son varios los autores que aluden al carácter no lineal del 
cibertexto. La idea fue apuntada por Mark Bernstein en 1988 y desarrollada con posterioridad en varios de sus estudios en los que describe las estructuras hipertextuales más comunes. También E. Aarseth la desarrolla como parte de su estudio sobre la evolución textual desde lo analógico a lo digital (1993; 1997). En el ámbito español José Luis Orihuela (1997) alude precisamente a este término para hablar de la nueva ficción hipertextual. Habría que considerar aquí como antecedente de este tipo de creación hipertextual a todos aquellos escritores que han buscado estrategias para suplir la linealidad analógica, porque, supuestamente, ésta falseaba su experiencia creadora. Son obras que ofrecen de forma manifiesta finales múltiples o conclusiones unidas a nuevos comienzos; novelas que de manera muy explícita y consciente se presentan como itinerarios que, al ser andados, construyen el relato inicialmente sólo virtual. Todas ellas fueron creadas para su transmisión en un formato impreso en los límites cerrados de la página. Pero al ser leídas en la actualidad, tras nuestra experiencia con el hipertexto, se revelan ante nuestros ojos como excelentes ejemplos de creación hipertextual, precisamente por su apertura no lineal. En todos estos casos estamos ante lo que la crítica ha denominado "literatura experimental" que comprueba la viabilidad de un modelo alternativo a la narración lineal.

Se suele comenzar citando como antecedente de esa ruptura de la linealidad algunos relatos de Borges, como "El libro de arena", "El jardín de los senderos que se bifurcan”, o "La Biblioteca de Babel". A decir verdad, estos textos suponen un antecedente de lo hipertextual más desde un punto de vista conceptual y metafórico que desde el puramente formal. La disposición de los libros en "La Biblioteca de Babel" encierra múltiples claves que preconizan la "Era Internet". Por supuesto también se suele citar Rayuela (1963) de Julio Cortázar que invita al lector a hacer su propia lectura, su propio recorrido del texto.

En el ámbito de la literatura española más reciente, quien mejor ha rastreado el intento de la novela por hacerse eco de los recursos multimedia es Francisco Gutiérrez Carbajo (1997) que alude a la novela Juego de cartas (1964) de Max Aub como antecedente, dado que su argumento se sujeta sobre las posibilidades combinatorias de un juego de cartas. Otro ejemplo es la novela de Arturo Pérez Reverte La piel del tambor (1995), que incorpora el tema de la literatura multimedia, aunque no como técnica narrativa. Otro caso 
es la novela de Laura Esquivel La ley del amor (1996) en la que se integran partes ilustradas y fragmentos que hay que escuchar con música, para lo cual se incorpora un CD. Mzungo (1996) de Luis Goytisolo se presenta también con un CD-ROM en el que vienen diferentes juegos relacionados directamente con el desarrollo de la novela. Otros ejemplos interesantes son: El amor en los tiempos del ch@t de Palma Infantes (Finalista del Premio Planeta de 1999), Sueños digitales (2000) de Edmundo Paz Soldán, o la recopilación de relatos de varias autoras Al otro lado un extraño (2001). Sin duda, como intenta explotar la propaganda comercial de estas obras, el mundo de las nuevas tecnologías utilizado como argumento es gancho seguro entre un público lector joven. A este fenómeno habría que sumar también el de los relatos literarios escritos por profesionales de la informática, cada vez más frecuentes. La revista Novática de la Asociación de Técnicos de la Informática viene publicando desde 1996 en su edición en papel, y también en su versión en la Red, ciertos relatos que tienen que ver con el mundo de la informática o están escritos por informáticos, aunque muchos de ellos aparezcan como anónimos o se publiquen bajo seudónimo.

Estos dos aspectos tratados - la experiencia de la colectividad y la ruptura de la linealidad - son dos características básicas para interpretar los antecedentes de la literatura hipertextual escrita en español y los ejemplos que hemos aducido constituyen, como dice el crítico Santos Sanz en el prólogo a La rebelión de los delfines, un "muestrario de modos de escritura y de modelos narrativos actuales" (2001: 26). Pero se puede dar un paso más: el objetivo es ahora, teniendo en cuenta estos antecedentes, reflexionar sobre la literatura hipertextual e hipermedial escrita en español hasta el momento (Romero López, 2007; 2008).

\section{2 - ALGUNOS TEXTOS DE LITERATURA DIGITAL ESCRITA EN ESPAÑOL}

El crítico de literatura en hipermedia tiene en estos momentos dos retos: ayudar a los lectores a localizar la literatura digital e ir ofreciendo calas de lectura e interpretación de dichos textos. La literatura pensada y escrita en red que desarrolla códigos y estructuras narrativas interdisciplinares es hoy una realidad naciente en el ámbito hispánico. Por lo general, el término literatura digital se refiere a géneros literarios relacionados con la 
ciberliteratura: hiperficción, hiperpoesía, hiperperformance, etc. La Electronic Literature Organization (http://www.eliterature.org/about) propone como característica sine qua non para la literatura digital sólo que contenga "important literary aspects". Pero ¿cuáles son esos aspectos literarios tan importantes?, ¿son un calco de los principios literarios propios de la tradición impresa o suponen un cambio en la definición del concepto mismo de literatura? Para algunos críticos la literatura digital implica un nuevo género literario, para otros sólo una nueva forma de experimentar con la literatura, o mejor, la única manera que la literatura tiene en la actualidad de experimentar nuevas formas de creación.

La literatura digital en español cuenta hoy en la red con algunos portales o directorios fundamentales: el de la Universidad de Pamplona, dirigido por José Luis Orihuela y dedicado a la hiperficción en español, la revista Hipertulia de la Universidad Complutense, la Web del grupo Hermeneia, de la Universidat Oberta de Catalunya, el portal de hiperficciones de la Universidad Pompeu Fabra, el Open Directory Project, en varios idiomas, entre ellos el español y el portal sobre relato digital de la Universidad Javeriana en Colombia. La mayoría de los autores son desconocidos para el público lector global, aunque siempre dejan algunos rastros interesantes en las obras publicadas en línea. La autoría suele ser compartida: colaboran inventores de la historia con los técnicos que la desarrollan en formato hipermedia. Hay bastantes proyectos de escritura digital hipertextual e hipermedia desarrollados por alumnos de periodismo, que han sido guiados por sus profesores para la realización de estos trabajos universitarios. Quizá por ello, los textos creados tienen un estilo bastante adaptado al gusto de la juventud actual. Se utilizan collages de chats y correos, se mezcla la imagen con música y palabras, se percibe una fuerte influencia del cómic. Los temas predilectos de estas jóvenes creaciones son las aventuras y los diarios. Los personajes son, en su mayor parte, jóvenes con problemas de jóvenes (identidad, amor-desamor, conflictos sociales).

Rastreando las huellas de hiperliteratura que hay en los directorios citados, observamos que contamos ya con un repertorio digno. A pesar de que la frontera entre los distintos géneros literarios en la virtualidad electrónica es muy imprecisa, la crítica sigue ofreciendo similitudes entre estos textos y los tres grandes géneros clásicos: poesía, prosa y teatro. 
Una característica de todos estos textos es que el creador cede al lector el poder de conducir el texto por donde quiera, pero siempre se guarda la carta de ir marcando el recorrido. Esta semiorganización se corresponde con la realización de un viejo sueño: el de hacer participar al lector en la elaboración de la obra. La lectura se entiende como camino, como recorrido, y todo lector avanza en el texto abriéndose camino entre unidades fragmentadas.

Estos repertorios particulares se van viendo apoyados por la aparición de premios y de eventos institucionales. En cuanto a los premios, en 2007 el Grupo de Investigación LEETHI (Literaturas Españolas y Europeas del Texto al Hipertexto) convocó un premio de literatura digital subvencionado por la Universidad Complutense y la Compañía Microsoft Ibérica S. A. El premio tenía tres modalidades: A) Edición electrónica de obras literarias escritas en español, B) Didáctica en línea de las literaturas en español y C) Literatura digital de creación en lengua española. En este último apartado - que es el que concierne aquí - el ganador fue Jaime Alejandro Rodríguez Ruiz (Colombia) por su obra Golpe de gracia. La obra encarna numerosas profecías respecto a la narrativa digital y su convergencia con los juegos de ordenador. Esta obra atrapa al lector en una rica madeja de intriga y misterio, en la que la historia de la muerte del padre Amaury se entremezcla con reflexiones sobre la cibercultura y los nuevos géneros narrativos, sobre la muerte y la vejez, los autoritarismos, el enfrentamiento entre el mundo de los jóvenes y el de sus mayores, entre la virtud y la corrupción moral. La obra consta de tres niveles o mundos: Cadáver exquisito, Línea mortal y Muerte digital, y cuatro salas (de juego, de lectura, de estudio, y de construcción). Cada uno de estos mundos nos ofrece un modo distinto de lectura: la contemplación de una representación cuasi teatral, el juego de habilidad y el de deducción. El lector se convierte en un explorador de un universo de ficción poblado por personajes que se irán tornando familiares, temas que nos harán reflexionar y niveles que se acabarán entrelazando. A través de sus distintas salas, Golpe de gracia nos ofrece una peculiar experiencia de lectura de los distintos textos que conforman la historia original, y en la que el lector es invitado también a participar en la construcción de un entorno de reflexión crítica sobre la cibercultura y sus productos, incluidos varios blogs sobre Golpe de gracia. El Jurado decidió conceder una Mención Especial a la obra Desnudo firmada por Carola Di Nardo (Argentina). Desnudo es una 
narración corta con formato hipertextual y factura manual de dibujos que recrea un micromundo rural donde se teje y se desteje a través de los cotilleos la historia de un hombre desnudo.

También las instituciones culturales españolas están tomando conciencia de las posibilidades literarias de la Web. De hecho durante el año 2008 , La Casa Encendida de la Comunidad de Madrid organizó el evento Yuxtaposiciones'08. Microfestival de poesía y polipoesía con recitales de Poetry Slam, una nueva forma de comunicación basada en textos polémicos, ritmo trepidante que inspira a jóvenes creativos a encontrar modos de expresar sus puntos de vista, críticas, problemáticas y les ofrece una nueva manera de "gritar" en el sentido literal del término, pero también de compartir y escucharse unos a otros. En estos recitales participaron D' de Kabal, Julio Jara y los Pimpipoets. Al encuentro asistieron también otros poetas, como el brasileño Ricardo Domeneck, el mexicano Eugenio Tisselli, la suiza Nora Gomringer, el canadiense Mark Sutherland y los catalanes Albert Pla y Josep Pedrals. Todo un encuentro internacional que pretende renovar la expresión literaria a través de los medios digitales.

\section{3 - EL CONTEXTO EN EL QUE SURGE LA LITERATURA DIGITAL EN ESPAÑOL}

Puesto que la literatura digital se asienta en el canal de comunicación de la Web, me parece interesante analizar cuatro aspectos fundamentales de ese proceso: a) vamos a comentar el contexto cultural que apoya el surgimiento de la literatura digital en español; b) desde el punto de vista del emisor determinaremos, quiénes son los autores de estos textos y por qué escriben literatura digital; c) desde el punto de vista del mensaje vamos a establecer el repertorio de textos que hemos encontrado, y d) por último, desde el punto de vista de la recepción, analizaremos a quiénes van dirigidos estos textos.

\section{a) Contexto}

El contexto en el que se promociona la literatura digital cuenta con una red de directorios o portales. Los más importantes son: 
- El de la Universidad de Pamplona, dirigido por José Luis Orihuela y dedicado a la hiperficción en español: http://mccd.udc.es/orihuela/hyperfiction/

- La revista Hipertulia de la Universidad Complutense:

\section{http://www.ucm.es/info/especulo/hipertul/}

- La Web del grupo Hermeneia, de la Universidat Oberta de Catalunya: http://www.uoc.edu/in3/hermeneia/cat/

- El portal de hiperficciones de la Universidad Pompeu Fabra: http://www.iua.upf.es/ berenguer/recursos/narr/portada.htm

- El Open Directory Project, en varios idiomas, entre ellos el español: http://dmoz.org/World/Espa\%c3\%b1ol/Artes/

- El portal sobre relato digital de la Universidad Javeriana en Colombia.

\section{b) Autores}

La mayoría de los autores son desconocidos ${ }^{1}$, pero siempre dejan algunos rastros interesantes en las obras publicadas línea. La autoría suele ser compartida: colaboran inventores de la historia con los técnicos que la desarrollan en formato hipertextual. Hay bastantes proyectos de escritura digital hipertextual desarrollados por alumnos de periodismo, que han sido guiados por sus profesores para la realización de estos trabajos universitarios. Quizá por ello, los textos creados tienen un estilo bastante adaptado al gusto de la juventud actual. Se utilizan collages de chats y correos, se mezcla la imagen con música y palabras, se percibe una fuerte influencia del comic. Los temas predilectos de estas jóvenes creaciones son las aventuras y los diarios. Los personajes son, en su mayor parte, jóvenes con problemas de jóvenes (identidad, amor-desamor, conflictos sociales).

No es baladí que la nueva literatura digital surja vinculada al ámbito universitario. Recuerdo al público que esto ha sido habitual a lo largo de la historia de la literatura: piénsese en los clérigos medievales en cuyos monasterios surgen las primeras

\footnotetext{
${ }^{1}$ Algunos de estos escritores son ya reconocidos poetas o narradores lineales, como Edith Checa, sevillana y finalista del premio Herralde de novela, Jaime Alejandro Rodríguez Ruiz, colombiano que ha publicado relatos, novelas y ensayos. Belén Gache es una escritora argentina con cierto reconocimiento tanto en España como en Hispanoamérica.
} 
universidades, en los humanistas del Renacimiento, los novatores del siglo XVIII o en buena parte de los intelectuales del siglo XX. La historia literaria en este sentido se repite: estamos ante una forma de literatura vinculada a creadores cultos. $Y$ detrás de todo creador culto existe una biblioteca que podemos establecer en virtud de los programas de estudio que se imparten en las universidades y de la que dejo constancia en nota a pie de página $^{2}$. Son generalmente libros que proceden del ámbito universitario anglosajón o sus traducciones vertidas ya al castellano.

\section{c) Repertorio}

Rastreando las huellas de hiperliteratura que hay en los directorios citados, observamos que contamos ya con un repertorio de veintiocho ejemplos que cito a continuación:

\footnotetext{
${ }^{2}$ Contamos con las bibliotecas que utilizan estos autores para la creación de sus hipertextos que se pueden consultar tanto en el sitio creado en la Universidad de Navarra como en el de A Coruña. El programa de estudio de la Universidad de Navarra se les recomienda a los alumnos los siguientes libros. Como textos básicos el de José Luis Orihuela y María Luisa Santos (1999). Introducción al diseño digital. Concepción y desarrollo de proyectos de comunicación interactiva. Madrid: Anaya Multimedia, y el de Octavio Rojas, Julio Alonso, José Luis Antúnez y José Luis Orihuela y Juan Varela (2005). Blogs. La conversación en Internet que está revolucionando medios, empresas y ciudadanos, Madrid: Editorial ESIC. Como bibliografía general se recomiendan los siguientes libros: Black, Roger (1997) Web Sites that Work, San José: Adobe Press. Bou Bauzá, Guillem (1997). El guión multimedia, Madrid: Anaya Multimedia. Davis, Jack, y Merrit, Susan (1999). Diseño de páginas web. Soluciones creativas para la comunicación en pantalla, Madrid: Anaya Multimedia. Fernández-Coca, Antonio (1998). Producción y diseño gráfico para WWW, Barcelona: Paidós. Garrand, Timothy (1997). Writing for Multimedia, Boston: Focal Press. Kristof, Ray y Satran, Amy (1998). Diseño interactivo, Madrid: Anaya Multimedia. Murray, Janet (2000). Hamlet en la holocubierta. El futuro de la narrativa en el ciberespacio, Barcelona: Paidós .Olsen, Gary (1997). Getting Started in Multimedia Design, Cincinnati: North Light Books. Siegel, David (1997). Secrets of Successful Web Sites. Project Management on the World Wide Web, Indianapolis: Hayden Books. Strauss, Roy (1997). Managing Multimedia Projects, Newton: Focal Press. Vaughan, Tay (1995). Todo el poder de multimedia, México: McGraw-Hill. En la Universidade de A Coruña en su máster sobre "Narrativa y Teoría de la Comunicación" -Financiado por la propia universidad y por la Fundación Caixagalicia- imparten las siguientes asignaturas: L. Hernández (UDC), "Mundos Digitales", J. L. Orihuela (UNAV), "Narración no lineal", M. L. Santos (UNAV), "Dirección y Diseño de Proyectos", R. Campos (Guionista), "Lenguaje y Guión Audiovisual", M. A. Paredes, "Técnicas de Trabajo en Equipo" e incluso de F. Escribano, "Videojuegos". También encontramos otras asignaturas dedicadas a las herramientas de creación y diseño de la Red, o animación en tres dimensiones. Al final del master se les pide a los alumnos que defiendan un corto de animación o un trabajo multimedia. Evidentemente, algunos de esos trabajos multimedia nos interesan a los filólogos porque son hipertextos narrativos.
} 
is

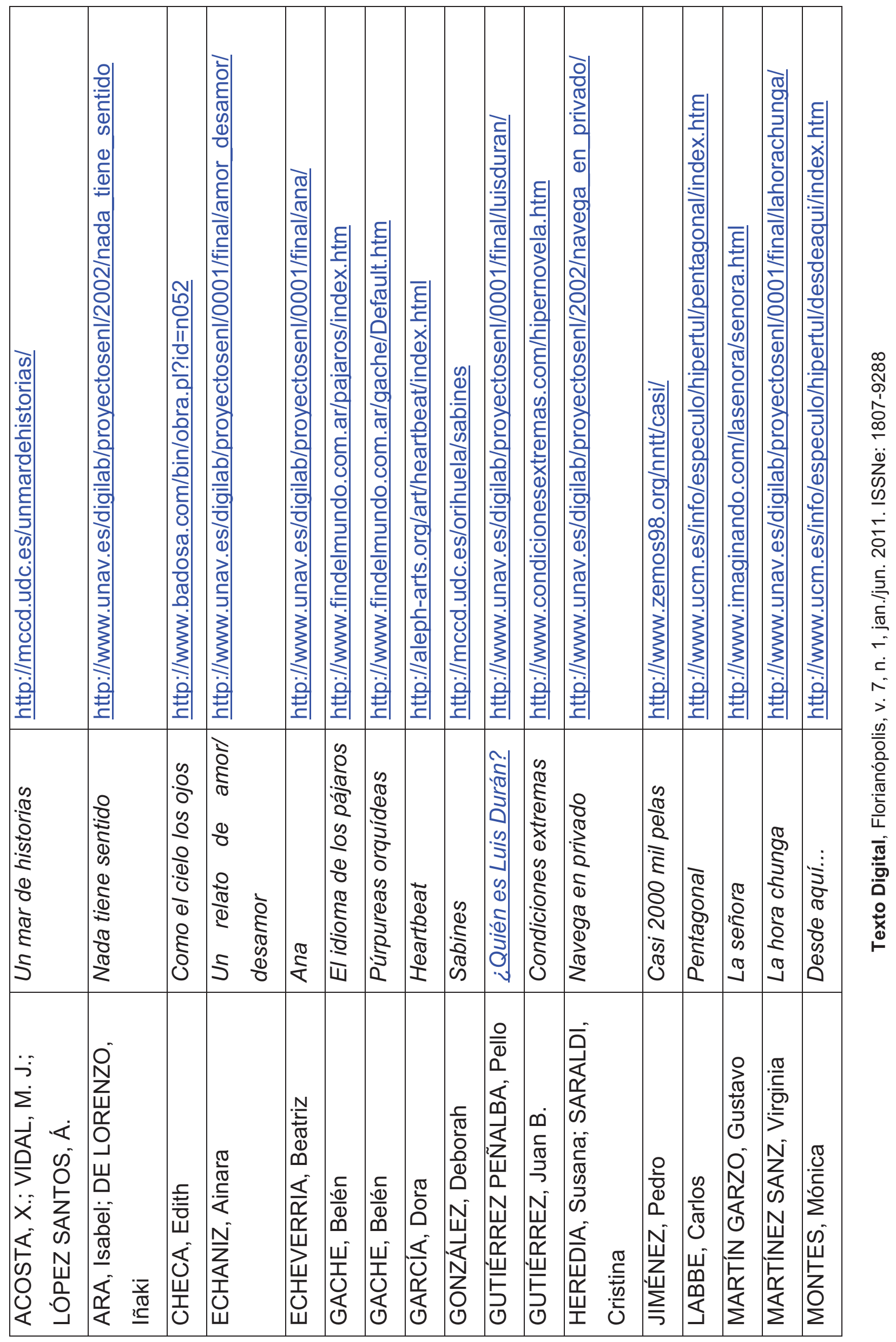




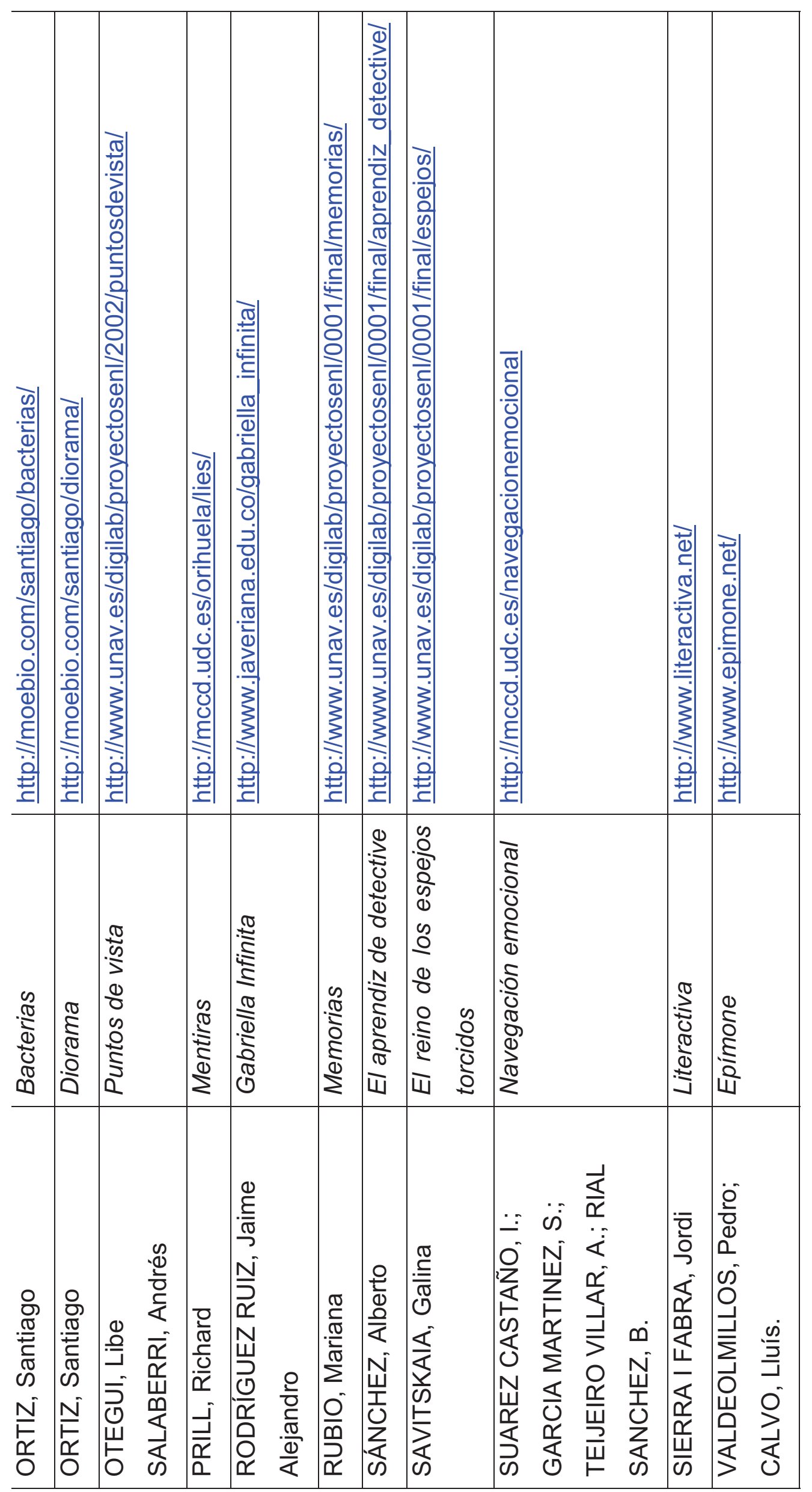

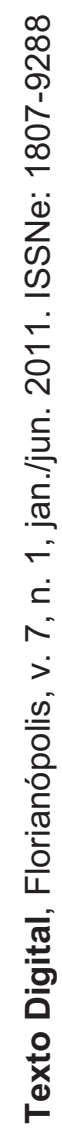


A pesar de que la frontera entre los distintos géneros literarios en la virtualidad electrónica es muy imprecisa, la crítica sigue ofreciendo similitudes entre estos textos y los tres grandes géneros clásicos: poesía, prosa y teatro ${ }^{3}$.

En el ámbito de la denominada hiperpoesía encontramos una gradación desde la más simple digitalización del poema a la hipertextualidad y creación de holopoesía, que es la forma más compleja de poesía hipertextual. El caso de Un relato de amor/desamor, de Ainara Echaniz, es una historia en la que se habla de amor, desamor entre adolescentes, en el que el lector selecciona textos según dos versiones: época feliz y época infeliz. Forman parte de la historia los poemas de amor del chileno Pablo Neruda, que se convierten en eje temático de esta narración ${ }^{4}$. Merece párrafo aparte el texto multilingüe de Belén Gache El idioma de los pájaros, en el que los pájaros cantan / recitan todos al unísono poemas de reconocidos poetas, cuyos protagonistas son precisamente pájaros: así escuchamos "Volverán las oscuras golondrinas” de Gustavo Adolfo Bécquer, "Leda" de Rubén Darío, “The raven” de Edgard Allan Poe, "Le paon” de Guillome Apollinaire y "Le cygne” de Charles Baudelaire.

Existen otros dos poemas que recogen toda una tradición de poesía experimental y de la que actualmente se denomina holopoesía. Se trata de dos textos de Santiago Ortiz. El primero, creado en el 2004 y titulado Bacterias, son palabras y frases en movimiento enlazadas unas con otras que al hacer clic en uno de los nódulos-lexías se reproduce, como si fuera una bacteria. Las supuestas bacterias léxicas tienen color en el centro dependiendo del tipo de alimento que comen. El grosor de su centro determina la energía de sus relaciones. Los distintos términos parecen extraídos de la teoría del caos o de la deconstrucción. El segundo texto creado por Santiago Ortiz es Diorama, constituido por una red relacional de conceptos, textos, imágenes, aplicaciones interactivas, enlaces y referencias en un espacio navegable. Los contenidos conforman un cúmulo de información y una reflexión en torno al lenguaje y los códigos. En particular identifica tres formas y usos de código que operan en ámbitos muy distintos a la vez que cercanos: código generador de vida [código genético], código generador de narración [lenguas] y código generador de modelos y sistemas de representación

\footnotetext{
${ }^{3}$ No encuentro, por ahora ningún texto teatral en los citados portales. Actualmente estoy coordinando a un grupo de investigadores que están investigando sobre "Teatro y Nuevas Tecnologías". Los resultados de su investigación se publicarán en la Revista Signa de la Asociación Española de Semiótica.

${ }^{4}$ Se seleccionan poemas de Cien sonetos de amor y de Veinte poemas de amor y una canción desesperada
}

Texto Digital, Florianópolis, v. 7, n. 1, jan./jun. 2011. ISSNe: 1807-9288 
[código informático]. Cuando uno se sumerge en este universo mecanizado parece como si estuvieramos dentro de la propia inteligencia artificial, donde la filosofía, la ciencia y la tecnología por fin están unidas recobrando un paraíso perdido.

En hiperficción hemos encontrado dos novelas. Una de ellas, muy conocida y estudiada, Condiciones extremas, del colombiano Juan B. Gutiérrez basada en una trama de intrigas, persecuciones, búsquedas, secuestros, enigmas, tras lo que late un deseo de poder, ambición, organización social, el racismo, el miedo, y ciertamente una reflexión crítica sobre los extremos a los que puede llegar el nivel de contaminación de nuestro planeta. Dicha trama de intriga se desarrolla más aún en su última obra: The first flight of the Wright Brothers (a pesar del título, sólo en español). Otra hipernovela es la de la sevillana Edith Checa Como el cielo los ojos, basada en vínculos y relaciones intertextuales. Una vez que pulsamos en el acceso a la novela, aparece ante nosotros una cuadrícula, en la que cada sección está ocupada por un ojo. En el eje vertical leemos tres nombres y el eje horizontal está numerado del uno al trece. Tres personajes, trece tiempos y una sola novela, un solo acontecimiento desencadenador: "Isabel ha muerto...".

Dentro de la diversidad de relatos cortos que hemos hallado podemos ofrecer una clasificación subgenérica:

1. Dentro de la "Ficción de intriga" cabe destacar el hipercuento de Libe Otegui y Andrés Salaberri Puntos de vista que describe una historia de unos personajes marginales que frecuentan un bar de la calle "Puesamonyola". Al subgénero de intriga policíaca pertenece el texto de Pello Gutiérrez Peñalba ¿Quién es Luis Durán? que nos ofrece dos formas de leer un relato, una lineal y otra intercactiva: un hombre desaparecido y objeto de la búsqueda de un inspector de policía y de su exmujer, que no se fía del inspector.

2. Un segundo subgénero de hiperficción es la autobiografía en el que se podría clasificar el texto de Isabel Ara e Iñaki Lorenzo Nada tiene sentido concebido como un diario digital de un narrador que está desesperado porque no puede salir de su habitación, lo único que puede hacer es escribir cómo se siente en la pantalla de su ordenador. Es un texto de gran originalidad, cuya trama progresa hasta que nos damos cuenta que estamos leyendo las reflexiones de 
un esquizofrénico que termina perdiendo el orden lógico de las palabras y que se vuelve literalmente loco. Incluso si vamos un poco más allá podemos pensar que ese loco que está delante de la máquina es nuestro propio yo. Este subgénero autobiográfico es la representación hipertextual de la identidad que entronca con la historia de la mentalidades en el que no es sólo el yo el centro de las creencias de la autobiografía moderna, no estamos sólo ante una desintegración del yo, sino ante la anulación de la identidad humana proscrita por la máquina. Un solipsismo que produce esquizofrenia, fragmentación de un yo real para disolverse en el espacio virtual.

d) Público

En todos los casos antes citados, el creador cede al lector el poder de conducir el texto por donde quiera, pero siempre se guarda la carta de ir marcando el recorrido. Esta semiorganización se corresponde con la realización de un viejo sueño: el de hacer participar al lector en la elaboración de la obra. La lectura se entiende como camino, como recorrido, y todo lector avanza en el texto abriéndose camino entre unidades fragmentadas. Esta es una característica consolidada.

\section{4 - EL RETO DE LA LECTURA EN PANTALLA}

En este momento parece conveniente sólo plantear posibles vías de entrada a las obras a través de las propias obras digitales y las reflexiones de sus escritores.

1 - El texto guiado y sin imágenes...

La primera vía de acceso a la lectura de textos literarios digitales es la lineal: el lector se deja llevar por el "enlace" y va leyendo una tras otra las páginas que componen el texto. Este es el caso de la obra de Isabel Ara e Iñaki Lorenzo Nada tiene sentido (http://www.unav.es/digilab/proyectosen//2002/nada tiene sentido/). Se trata de un diario digital en el que un narrador describe su desesperación porque no puede salir de su habitación, lo único que puede hacer es escribir en su ordenador cómo se siente. Dice: He decidido seguir con estas páginas Web y utilizarlas como diario. De pequeño 
tenía uno de papel, pero me cansaba tener que utilizar la pluma para contar mi vida. La mayoría de los días mi vida era tan gris que no merecía el esfuerzo de escribirla".

Esta obra está compuesta utilizando los nuevos géneros discursivos digitales: el correo electrónico y el chat (López Alonso, Seré, 2003), que el narrador copia y pega en su diario virtual. El argumento es simple, está muy bien contado y distribuido formalmente: El narrador quiere comunicarse con otros personajes para que le socorran de su soledad, pero no lo consigue: su novia está de viaje y otros internautas anónimos no le creen. Trata de comunicarse con la policía o el Samur - servicio de emergencias —, pero no le prestan atención: todos parecen tomarle por un loco. De repente, aparece un internauta anónimo que contacta con un psiquiatra, que resulta ser el mismo psiquiatra que está tratando al narrador. El psiquiatra advierte al internauta que la persona con la que se está comunicando a través de los correos electrónicos es un esquizofrénico que presenta síntomas de alucinaciones, delirios, pensamientos desordenados y conducta extrañas. Al final todo se resuelve: el narrador es un tal Pedro Martínez SanMiguel que está internado en el psiquiátrico que dirige el afamado psiquiatra de la Clínica San Cristóbal. Se confirma la sospecha del lector: el diario es el de un esquizofrénico, quien al final tiene una crisis de identidad: su texto va perdiendo la coherencia y cohesión, es decir, el orden lógico de las palabras. Fondo y forman convergen en la esquizofrenia, en la locura del narrador digital.

Este texto puede enclavarse dentro del subgénero autobiográfico (Durán López, 2005), pero aquí hay unas características propias de la identidad solipsista digital: el yo ya no es sólo el centro de las creencias de la autobiografía moderna, sino que estamos en una desintegración de la identidad propia de la posmodernidad, aún más, nos encontramos ante la anulación de la identidad humana proscrita por la máquina. El aislamiento produce la esquizofrenia, una escisión de la identidad, una fragmentación de un yo encerrado en una habitación y en una máquina al mismo tiempo. Pero lo más preocupante es el reconocimiento de que más allá de la entropía digital nadie le hace caso, nadie le entiende, nadie le toma en serio. 


\section{2 - Literatura hipermedia}

La segunda vía de acceso a la entropía digital es aquella en la que el lector puede dejarse llevar por distintos "enlaces" al mismo tiempo. Además en este tipo de gravitación lectora el hipertexto se convierte en hipermedia, es decir, pierde la linealidad textual para rotar también en torno a la imagen e incluso a la oralidad. Este es el caso del texto de Belén Gache El idioma de los pájaros (http://www.martagonzalezobras.com.ar/adigitales/gache/idiomapajaros.htm), en el que los pájaros cantan/recitan todos al unísono poemas de reconocidos poetas, cuyos protagonistas son precisamente pájaros: Así escuchamos "Volverán las oscuras golondrinas" de Gustavo Adolfo Bécquer, "Leda" de Rubén Darío, "The raven" de Edgard Allan Poe, "Le paon" de Guillome Apollinaire y "Le cygne" de Charles Badelaire. La autora nos indica cuál es su objetivo en la creación de estas poesías:

Los pájaros han sido tradicionalmente símbolo de sentimientos o propiedades humanas. Muchas historias nos cuentan, incluso, acerca de la facultad de palabra que poseen ciertas aves. Esta facultad es, sin embargo, ocultada a los hombres. Algunos pocos han podido, no obstante, compartir el secreto. Entre ellos, Anaximandro, Apolonio de Tiana (curiosamente, los dos eran magos) y el mismo Esopo.[...]

Los pájaros de "El idioma de los pájaros" son máquinas-poetas. En este sentido, comparten con el ruiseñor mecánico, en primer lugar, la paradoja de combinar una fragilidad extrema con una armadura rígida $y$ monstruosa. También comparten el hecho de estar programados para re-citar palabras. ¿Acaso las palabras no son siempre ajenas? [...]

Además de las aves autómatas, en "El idioma de los pájaros" hay otro tipo de aves, incluso más aberrantes todavía: las que están hechas únicamente de palabras. Cisnes, golondrinas, cuervos y ruiseñores se nos presentan como pájaros lingüísticos, capturados por las máquinaspoetas dentro de una inviolable armadura significante.

Esta es la trágica canción de los pájaros de "El idioma de los pájaros": cuanto más cantan, más irremediablemente prisioneros quedarán de la jaula del lenguaje

La golondrina, los cisnes, el grajo, el pavo y la cigüeña emiten su propio canto y quedan representados en una lámina animada donde aparecen los cinco pájaros cantando en la misma imagen, texto y sonido en un deseo muy querido y buscado por la poesía visual auditiva, experimental. Este poema recoge, por un lado, la tradición hispánica y europea del letrismo y, por otro, el internacionalismo lingüístico vanguardista (Cózar, 1991). 
¿Qué aporta este tipo de literatura digital a la que ya denominamos literatura visual o experimental analógica? Nuevamente, como en el caso anterior - el esquizofrénico —, el yo lírico (pájaro) está prisionero en la jaula (entropía digital), convertido ahora en una máquina poeta. El yo creador se nos presenta encerrado dentro de la máquina, como si se tratara de un simulacro del film Matrix.

\section{3 - La gravitación rizomática: la hololiteratura}

La tercera vía de acceso a la entropía digital es aquella en la que el lector se deja llevar por la gravitación de un mundo virtual bidimensional o tridimensional. Aunque no es un género muy abundante por la dificultad creativa que entraña, existen algunos ejemplos. Lo que más llama la atención de la hololiteratura es que parece ser generada por el propio ordenador. Este es el caso de dos poemas del argentino Santiago Ortiz. El primero fue creado en el 2004 y se titula Bacterias. Retrata de palabras y frases en movimiento enlazadas. Cuando se hace clic en uno de los nódulos-lexías, éste se reproduce como si fuera una bacteria. Las supuestas bacterias léxicas tienen color en el centro dependiendo del tipo de alimento que comen y el grosor de su centro determina la energía. Las relaciones entre los distintos términos parecen sacadas de la teoría del caos o de la deconstrucción. El segundo texto creado por Santiago Ortiz en Medialabmadrid en el 2004 titulado Diorama es una red relacional de conceptos, textos, imágenes, aplicaciones interactivas, enlaces y referencias en un espacio navegable. Los contenidos conforman un cúmulo de información y una reflexión en torno al lenguaje y los códigos. Se identifican tres usos de código que operan en ámbitos muy distintos a la vez que cercanos: código generador de vida [código genético], código generador de narración [lenguas] y código generador de modelos y sistemas de representación [código informático]. Más importante que la compilación de la información es el entramado de relaciones. Diorama es el resultado de un trabajo que se inicia con la exposición El inventor de historias (Medialab Madrid, Centro Cultural Conde Duque, Madrid, abril-mayo 2004), en donde las paredes de la sala de exposición fueron cubiertas con textos e imágenes, relacionados entre sí y con instalaciones y aplicaciones digitales también expuestas (en la página de la exposición es posible ver una fotografía del montaje). La red de de textos, imágenes y aplicaciones puede ser explorada recorriendo los contenidos a través de las relaciones. De esta forma cada recorrido es un viaje particular, una narrativa, a través del conocimiento. Aunque cada 
nodo (contenido) es representado en un espacio tridimensional, rodeado de sus nodos relacionados, el espacio-red posee múltiples dimensiones asociadas a la topología de la red.

Antes de entrar en esas obras, el lector recibe información sobre el funcionamiento de este texto sacado de la geometría fractal, que está a mitad camino entre las matemáticas, el arte y la concepción de unas reflexiones filosóficas. Si lo clasificamos como obra experimental es por el juego que nos ofrecen los conceptos, enlazados sin demasiada lógica discursiva, pero que llevan al lector a preguntarse sobre una posible reflexión propia. Es decir, en la hololiteratura la obra se organiza en una geometría no lineal en un espacio tridimensional inmaterial y que a medida que el lector o el espectador lo observa, el poema muta y da lugar a nuevos significados. El lector no salta de unas páginas a otras mediante links, lo que parece obedecer más al juego, al instinto. En la lectura de la hololiteratura hay que tener en cuenta tanto la selección que el poeta ha hecho de las palabras y las relaciones que dichas palabras mantienen entre ellas. El artista busca una obra de arte total donde se confunden distintos códigos sígnicos. El lector siente cierto extrañamiento ante estas obras, además se ve obligado a participar más activamente en ellas. ¿Qué se busca? Se podría pensar que el relativismo, la pérdida de la hegemonía y de la racionalidad del lenguaje escrito. La perspectiva del juicio crítico, el desarrollo de lo cognitivo (comunicación de sensaciones, emociones y conceptos) dan idea de la existencia cambiante, como la realidad misma, el tiempo y el espacio cambian según la contingencia de cada lector, con lo que se genera la acronía y la utopía. El ritmo está basado en la sensación de inestabilidad textual que llega a ser emocional porque lo que realmente pretende el artista holográfico es demostrar la teoría de la imposibilidad de estructuras cerradas.

En conclusión, Internet no es sólo comunicación e información, es además, cultura. Internet es un espacio global que admite lo local, con lo que surge la glocalización transcibercultural lo que justifica que hablemos de literatura digital aplicado sólo para aquellas obras pensadas y escritas en español. La literatura digital es una manifestación más de la cibercultura. Algunas de las características atribuibles a la literatura digital - la experimentación de la colectividad y la ruptura de la linealidad narrativa - son demostrables en los relatos literarios de la novela colectiva y experimental hispánica. Además contamos con algunos ejemplos pioneros de obras 
literarias digitales escritas en español en los que se puede comprobar ciertos valores específicos que brotan de su propia virtualidad. Hemos presentado nuestro particular acercamiento a dichas obras teniendo en cuenta tres vías. En primer lugar, se encuentra la gravitación lineal que presenta un texto guiado y sin imágenes compuesto por géneros discursivos propios de las textualidades electrónicas. En segundo lugar, la gravitación helicoidal nos lleva a textos de literatura hipermedia en los que la linealidad textual rota además en torno a la imagen y sonidos. $Y$ por último, la gravitación rizomática nos transporta a la hololiteratura en la que el lector se deja llevar por la gravitación de un mundo virtual bidimensional o tridimensional. Así pues, desde la colectividad y el deseo de ruptura de la linealidad como formas de experimentación literaria llegamos a la esquizofrenia, al solipsismo y al caos como expresión de un yo creador que manifiesta así su ser en la entropía digital.

\section{5 - NUEVA LITERATURA Y NUEVA CRÍTICA}

Progresivamente las posturas más radicales, la de los apocalípticos, por un lado, y la de los fanáticos de la informática por otro, se van atenuando para dejar paso a una reflexión en la que participan primordialmente los teóricos de la literatura y de la comunicación. La adaptación de los textos literarios a las nuevas formas tecnológicas digitales y la creación de textos creativos compuestos para ser vistos en pantalla parecen estar proporcionando una ocasión excelente para reflexionar sobre las nuevas formas del discurso digital. Todo ello ha contribuido a que algunos estudios teóricos comenzando por Moulthrop (1989), Landow (1991; 1995; 2006) y Aarseth (1997) contribuyan a alimentar un nuevo paradigma hipertextual para los estudios literarios, bien sea para apoyar los cambios trascendentales de este proceso o para ir aquilatando lo que, en un principio, se vio como una revolución del ámbito literario. Siguiendo los pasos de estos teóricos se han publicado numerosos trabajos. Hay bastantes apuestas que se quedan en el cambio de lo lineal a lo virtual (Laufer, 1995; Anis, 1998; Codina, 2000) otras muchas que apuestan por la didáctica (Mena, 2000; Botley, 2000), unas preocupadas por la estructuración y ordenación de la Web (Caridad y Moscoso, 1991) y cada vez más que centran sus estudios en la relación entre hipertexto y humanidades o, más específicamente, hipertexto y literatura (Landow, 1991; 1997; Moreno Hernández, 1998). 
En España se ha venido alimentando este cambio a través de varias publicaciones. Como figura pionera destaca Jenaro Talens cuando publicó el capítulo "El lugar de la teoría de la literatura en la era del lenguaje electrónico" (Villanueva, 1994) donde se plantea muchas preguntas sobre el lugar de la literatura en este nuevo universo. En 1995 publicará Escritura contra simulacro. El lugar de la literatura en la era de la electrónica (1995) en el que aduce que puesto que los sujetos sociales actuales no son los mismos que dieron lugar a lo que hoy conocemos como literatura, dicho concepto debe ser puesto en cuestión. Esta visión nihilista de lo literario en el ámbito de las nuevas tecnologías se deja ver también en su texto "El robot ilustrado y el futuro de las Humanidades" (2000). Evidentemente Jenaro Talens se hace eco de la visión apocalíptica del hecho literario ofrecida por Alvin Kernan en The Death of Literature (1990) y del enunciado de Michaels y Knapp (1982) sobre el "fin de la teoría", pero abre camino al lenguaje electrónico como el nuevo universo articulado.

Con el nuevo siglo se abren nuevas propuestas. En el año 2000 se publica el texto Literatura e Hipermedia. La irrupción de la Literatura interactiva: precedentes y crítica. Su autora, Nuria Vouillamoz, ofrece una reflexión sobre los modelos del hipertexto y los multimedia sin olvidar la literatura electrónica (dinámica, interactiva, de autoría abierta, etc.). María José Vega en Literatura hipertextual y teoría literaria (2003) parte en la introducción de un cierto escepticismo ante este nuevo cambio, lo que no es objeción para prestar la atención merecida a la reciente literatura hipertextual. El recorrido temático del libro abarca desde el hipertexto, la tradición y el canon, la literatura hipertextual y la realidad virtual y la lectura hipertextual. En el ámbito de la Universidad Carlos III de Madrid surge primeramente la vasta investigación de Antonio Rodríguez de las Heras sobre las nuevas tecnologías y el saber humanístico (2001; 2004). Siguiendo sus pasos, Domingo Sánchez-Mesa publica Literatura y cibercultura (2004) que se justifica por la necesidad de ocuparse de los retos que el nuevo paradigma comunicativo plantea a la literatura, más allá de la utilización de las herramientas informáticas (y no en red) en una fase empírica del estudio filológico. Susana Pajares Tosca publica su tesis bajo el título de Literatura digital. El paradigma hipertextual (2004) que aporta por primera vez en nuestra lengua un análisis de los primeros rasgos del nuevo paradigma hipertextual: multilinealidad, multimedia, multiplicidad, interacción, dinamismo, conexión. En el año 2005 apareció en las librerías el volumen titulado Textualidades electrónicas. Nuevos escenarios para la literatura editado por Laura 
Borràs y en el que encontramos un nuevo avance de la problemática interdisciplinaria literatura-tecnología: la literatura digital y el cuestionamiento del sujeto posthumano dentro del escenario de Internet. El volumen de Anxo Abuín y Teresa Vilariño, Teoría del hipertexto. La literatura en la era electrónica que vio la luz en el año 2006 con traducción de artículos canónicos de E. Aarseth, J.D. Bolter, J. Clément, P. Delany, J. Y. Douglas y M. Joyce. En este volumen se esboza la necesidad de una "inteligencia conectada" que nos permita crear vínculos de conexión a través de grupos de trabajo para emprender la tarea urgente de involucrar en nuestros estudios literarios, los nuevos avances digitales. Los recientes volúmenes Literatures in the Digital Age: Theory and Praxis (Sanz; Romero, 2007) y Literaturas del texto al hipermedia (Romero y Sanz: 2008) muestran los resultados de un Seminario Internacional celebrado en la Universidad Complutense del 21 al 23 de septiembre de 2005 organizado por el Grupo de Investigación LEETHI ("Literaturas en Español del Texto al Hipermedia”) y el Comité de Investigación "Comparative Literature in the Digital Age" de la AILC/ICLA. Ambos libros exponen las principales investigaciones presentadas en ese encuentro tanto de orden nacional como internacional y que suponen el deseo de parte de los organizadores de la creación de esa "inteligencia conectada" a través de grupos de investigación nacionales e internacionales, es decir, capaces de trabajar desde el yo al nosotros.

Hoy estamos más convencidos que nunca de que las literaturas del futuro serán hipertextuales o no serán. El soporte electrónico no es en sí garantía de innovación literaria o didáctica, lo sabemos. De hecho hay demasiadas páginas digitales que sólo son eso: digitalización de contenidos. Eso no basta. La novedad estará en el modelo conceptual con el que hagamos funcionar los recursos y los materiales, en el sistema cognitivo que pretendamos activar. Los estudiosos de las literaturas tenemos una función añadida inminente: trasladar nuestras ideas al formato cognitivo reticular de la web, si no lo hacemos, no terminaremos de cerrar el círculo, de enfrentarnos con la creación de ese nuevo paradigma, con sus retos y sorpresas.

\section{REFERÊNCIAS}

AARSETH, Espen. Nonlinearity and Literary Theory. In: LANDOW, G. P. (ed.) Hypertext and Literary Theory. Baltimore: Johns Hopkins Press, p. 51-86, 1993. 
Traduzido em: No linealidad y teoría literaria. In: LANDOW, G. P. (comp.) Teoría del Hipertexto. Barcelona: Paidós, 1997.

Cybertext. In: Perspectives on Ergodic Literature. Baltimore: The Johns Hopkins University Press, 1997.

ABUÍN, Anxo; Teresa VILARIÑO. Teoría del hipertexto. In: La literatura en la era electrónica. Madrid: Arco Libros, 2006.

ANIS, Jacques. Texte et ordinateur: l'écriture réinventée. Paris-Bruxelles: De Boeck, 1998.

BERNSTEIN, Mark. The Bookmark and the Compass: Orientation Tools for Hypertext Users. In: SIGOIS Bulletin. 9, p. 34-45, 1988.

BOTLEY, Simon (ed.). Multilingual Corpora in Teaching and Research. Amsterdam: Rodopi, 2000.

CARIDAD, Mercedes; Purificación MOSCOSO. Los sistemas de hipertexto e hipermedios. In: Una nueva aplicación documental. Madrid: Fundación Germán Sánchez Rupérez, 1991.

CASACUBERTA, David. Creación colectiva. In: En Internet el creador es el público. Barcelona: Gedisa, 2003.

CODINA, Lluis. EI libro digital y la WWW. Madrid: Tauro Producciones, 2000.

COTTE, Pierre (ed.). Language et Linéarité. Paris: Septentrion, 1999.

CÓZAR, Rafael de. Poesía e imagen. In: Formas difíciles de ingenio literario. Sevilla: Ediciones El Carro de la Nieve, 1991.

DELGADO, Silesio. Las vírgenes locas. Ed. de Rafael Reig. Madrid: Lengua de Trapo, 1999.

DOUGLAS, J. Y. What Hypertexts Do That Print Narratives Cannot. In: The Reader. p. 1-23, 1992.

DURÁN LÓPEZ, Fernando. Vidas de Sabios. In: El nacimiento de la autobiografía moderna en España (1733-1848). Madrid: Consejo Superior de Investigaciones Científicas-Instituto de la Lengua Española, 2005.

ESCOBAR, Arturo. Welcome to Cyberia: Notes on the Athropology of Cyberculture. In: Current Anthropology, 35, p. 211-223, 1994.

ESQUIVEL, Laura. La ley del amor. Barcelona: Plaza \& Janés, 1996.

GÓMEZ TRUEBA, Teresa. La literatura electrónica y sus antecedentes en la cultura impresa. $2005 . \quad$ Disponível

<http://www.liceus.com/bonos/compra1.asp?idproducto=509>. 
GOYTISOLO, Luis. Mzungo. Barcelona: Mondadori, 1996.

GUTIÉRREZ CARBAJO, Francisco. El intento de la novela multimedia. In: ROMERA CASTILLO, J; GUTIÉRREZ CARBAJO, F; GARCÍA-PAJE, M. Literatura y multimedia. Madrid: Visor Libros, p.234-245, 1997.

HAKKEN, David. Cyborgs@Cyberspace: an Ethnographer looks to the future. Londres: Routledge, 1999.

HAWK, Andy. Future Culture Manifesto. 1993. Disponível em: <http://project.cyberpunk.ru/idb/future_culture_manifesto.html>.

KERNAN, Alvin. The Dead of Literature. New Haven/Londres: Yale University Press, 1990.

LANDOW, George. Hypermedia and Literary Studies. Cambridge: MIT, 1991.

- Hipertexto. In: La convergencia de la teoría crítica contemporánea y la tecnología. Barcelona: Paidós, 1995.

. Teoría del hipertexto. Barcelona: Paidós, 1997.

. Hypertext 3.0: New Media and Critical Theory in an Era of Globalization. Baltimore: The John Hopkins University Press, 2006.

LÉVY, Pierre. Cibercultura. Barcelona: Anthropos, 2007.

LISTER, Martin. New Media: A Critical Introduction. Londres: Routledge, 2003.

LÓPEZ ALONSO, Covadonga; SÉRÉ, Arlete, (ed.). Nuevos géneros discursivos: los textos electrónicos. Madrid: Biblioteca Nueva, 2003.

MANOVICH, Lev. New Media from Borges to HTML. In: WARDRIP-FRUIN, N.; MONTFORT, N. (ed.). The New Media Reader. Massachussetts: MIT Press, p. 7-17, 2003.

MENA MERCHÁN, Bienvenido. Didáctica y nuevas tecnologías en educación. Madrid: Editorial Escuela Española, 2000.

MORENO HERNÁNDEZ, Carlos. Literatura e hipertexto. In: De la cultura manuscrita a la cultura electrónica. Madrid: UNED, 1998.

MOULTHROP, Stuart. In the Zones Hypertext and the Politics of Interpretation. 1989. Disponível em: <http://iat.ubalt.edu/moulthrop/essays/zones.html>.

Something to Imagine: Literature, Composition, and Interactive Fiction. In: Computers and Composition, 9, p. 7-23, 1991.

ORIHUELA, José Luis. Narraciones interactivas: el futuro no-lineal de los relatos en la era digital. Palabra-Clave, (2)2, p. 37-45, 1997. 
PAJARES TOSCA, Susana. Literatura digital: el paradigma hipertextual. Cáceres: Universidad de Extremadura, 2003.

PAZ SOLDÁN ÁVILA, Edmundo. Sueños digitales. Madrid: Ediciones Alfaguara, 2001. PÉREZ-REVERTE, Arturo. La piel del tambor. Madrid: Alfaguara, 1995.

ROBERTSON, Roland. Glocalización: tiempo-espacio y homogeneidad-heterogeniedad In: Cansancio del Leviatán: problemas políticos de la mundialización. Madrid: Trotta, 2003.

RODRÍGUEZ DE LAS HERAS, Antonio. Nuevas tecnologías y saber humanístico. In: GARCIA, Luis Ribot; BARUQUE, Julio Valdeón; PAZ, Ramón Villares (coord.). Año mil, Año dos mil. Dos milenios en la historia de España. Madrid: Sociedad Estatal España Nuevo Milenio, p. 59-70, 2001.

Experiencias con un libro digital. In: PEDRO M, Cátedra; LÓPEZ-VIDRIERO, María Luisa (ed.). La memoria de los libros. Salamanca: Instituto de Historia del Libro y de la Lectura, p. 13-17, 2004.

ROMERO LÓPEZ, Dolores. Spanish Literature in the Digital Domain: Culture, Nation and Narrations. In: SANZ CABRERIZO, A., ROMERO LÓPEZ, D. (ed.). Literatures in the Digital Era: Theory and Praxis. New Castle: Cambridge Sholars Publishing, p. 329340. Traduzido em 2008. Literaturas del texto al hipermedia, Barcelona: Anthropos, 2007.

ROMERO LÓPEZ, Dolores; SANZ CABRERIZO, Amelia (ed.). Literaturas del texto al hipermedia. Barcelona: Anthropos, 2008.

SÁNCHEZ-MESA, Domingo (ed.). Literatura y cibercultura. Madrid: Arco Libros, 2004.

Los estudios literarios y las humanidades en la cibercultura. In: SANZ CABRERIZO, Amelia. Teoría literaria española con voz propia. Madrid: Arco, 2009.

SANTONJA, Gonzalo. La modalidad de la novela colectiva. In: La novela revolucionaria de quiosco (1905-1939). Madrid: El Museo Universal, 157-180, 1993.

SANZ CABRERIZO, Amelia; LLAMAS, Miriam (ed.). Transliteraturas. In: SANZ CABRERIZO, Amelia. Teoría literaria española con voz propia. Madrid: Arco, 23-48, 2009.

Literatures in the Digital Age: Theory and Praxis. Newcastle: Cambridge Scholar Pressing, 2007.

SANZ VILLANUEVA, Santos. Prólogo. In: La rebelión de los delfines. Madrid: EspasaCalpe, 2001.

SILVA, Lorenzo. La isla del fin de la suerte. Barcelona: Círculo de Lectores, 2001.

TALENS, Jenaro. Escritura contra simulacro. In: El lugar de la literatura en la era de la electrónica. Valencia: Episteme, 1995.

Texto Digital, Florianópolis, v. 7, n. 1, jan./jun. 2011. ISSNe: 1807-9288 
. El robot ilustrado y el futuro de las Humanidades. In: El sujeto vacío. Cultura y poesía en territorio Babel. Madrid: Cátedra/Universitat de València, p. 394-407, 2000.

TORRES, David. Clarín y Las vírgenes locas: doce autores en busca de una novela. In: Cuadernos hispanoamericanos, 415, p. 53-63, 1985.

TOSCHI, Luca. Hypertext and Authorship. In: NUNBERD, Geoffrey (ed.). The Future of the Book. Berkeley: University of California Press, p. 69-207, 1996.

VEGA, María José (ed.). Literatura hipertextual y teoría literaria. Madrid: Marenostrum, 2003.

VILLANUEVA, Darío. Curso de teoría de la literatura. Madrid: Taurus, 1994.

VOUILLAMOZ, Nuria. Literatura e Hipermedia. In: La irrupción de la literatura interactiva: precedentes y crítica. Barcelona: Paidós, 2000.

VV. A. A. Las vírgenes locas. Madrid: Ediciones Lengua de Trapo, 1999.

La rebelión de los delfines. Madrid: Espasa-Calpe, 2001. 